\title{
GENETIC STRUCTURE CONFIRMS FEMALE-BIASED NATAL DISPERSAL IN THE WHITE-TAILED EAGLE POPULATION OF THE CARPATHIAN BASIN
}

\author{
Edina Nemesházi ${ }^{1,2}$, Krisztián Szabó ${ }^{1}$, Zoltán Horváth ${ }^{3}$ and Szilvia Kövér ${ }^{1}$ \\ ${ }^{1}$ Department of Ecology, University of Veterinary Medicine, H-1077 Budapest, Rottenbiller u. 50, \\ Hungary; E-mails: kr.szabo@gmail.com, kover.szilvia@univet.hu \\ ${ }^{2}$ Lendület Evolutionary Ecology Research Group, Plant Protection Institute, Centre for \\ Agricultural Research, Hungarian Academy of Sciences, H-1022 Budapest, Herman Ottó út 15, \\ Hungary; E-mail: nemeshazi.edina@agrar.mta.hu; corresponding author \\ ${ }^{3}$ Danube-Dráva National Park Directorate \\ H-7625 Pécs, Tettye tér 9, Hungary; E-mail: retisas.hu@gmail.com
}

Individuals can avoid inbreeding or competition with kin via long-distance natal dispersal. On the other hand, staying close to the well-known natal area may be a safer choice with respect to recruiting opportunities, reproductive success and the individual's survival probability as well. Natal dispersal strategy often differs between sexes, being generally female-biased in birds. We explored if the Carpathian Basin White-tailed Eagle population shows fine scale genetic structure and if it does, what is the extent of philopatry in the two sexes. We furthermore investigated sex bias in natal dispersal distance inferred from spatial distributions of genetically close relative breeding females and males. Spatial autocorrelation analyses failed to find fine-scale genetic structure, despite the species being known to be philopatric. Pairwise breeding distances of close relatives showed female bias according to Wilcoxon rank sum test. The median distance of two close relative females was 136 $\mathrm{km}$, while it was only $38 \mathrm{~km}$ in males. Since White-tailed Eagles are known to be faithful to their breeding territory, we assumed that the breeding distance between an individual and its parents refers to the individual's natal dispersal distance. Due to the same reason, the breeding distance of two siblings should also be related to their individual dispersal distances from their shared natal area. Therefore, we argue that the difference we found between sexes in pairwise breeding distances of close relatives stands for a female-biased natal dispersal. This bias may be a consequence of the species' breeding strategy, and it decreases the inbreeding probability as well.

Keywords: Haliaeetus albicilla, raptor, natal dispersal, genetic relatedness, Carpathian Basin.

\section{INTRODUCTION}

Individual dispersal strategy has substantial influence on the population or even species level traits such as population structure, genetic variability, level of inbreeding, metapopulation dynamics and speciation. Background of dispersal can be complex and is yet to be fully understood (MATTHYSEN 2005). The permanent movement that an individual makes from its natal area to the area where it first attempts to breed is referred to as 'natal dispersal', and its subsequent movements between its successive breeding areas are re- 
ferred to as 'breeding dispersal' (GREenwood \& HARvey 1982). Estimation of natal dispersal distance (NDD; i.e. distance between the natal and first breeding place of an individual) can provide important information related to evolution, ecology and conservation of a species. Long-distance natal dispersal for example can be a successful strategy to avoid inbreeding or competition with kin or more experienced adults for resources and mates (GREENWOOD \& Harvey 1982, Perrin \& Mazalov 2000). On the other hand, a strategy of short NDD (also referred to as philopatry) can be beneficial as well: moving within a restricted, familiar area, the individual can re-establish a territory just becoming vacant (SMITH 1978), knowing its available resources for feeding and reproduction; in addition, the costs derived from crossing less suitable or even dangerous areas during dispersal may decrease as well (YoDer et al. 2004). On population level, long-distance dispersal can allow colonization of suitable distant habitats and facilitate gene flow between populations being far apart from each other. In general, long-distance dispersal increases the genetic diversity within (sub)populations and decreases the genetic differentiation between them. By contrast, populations of a strictly philopatric species exhibit strong population genetic structure and show heterozygote deficiency on a metapopulation level (e.g. see Ortego et al. (2008) for genetic structure of Lesser Kestrels Falco naumanni (Fleischer, 1818), and Monti et al. (2018) for that of Osprey Pandion haliaeetus (Linnaeus, 1758)).

Philopatry was found in several species with high migration capability, such as many birds and mammals (Greenwood \& Harvey 1982, Pusey 1987, Alcaide et al. 2009, Whitfield et al. 2009a). Average NDD can differ between sexes and if so, it is usually male-biased in mammals and female-biased in birds (Greenwood \& Harvey 1982, Pusey 1987). Sex-biased natal dispersal strategies may predominantly be consequences of intrasexual or kin competition for territories, food resources or mates, given that these factors are unbalanced between sexes. Furthermore, sex-biased natal dispersal may serve inbreeding avoidance as well (Greenwood \& Harvey 1982, Perrin \& Mazalov 2000). Territorial birds generally have a so called resource defence system, where males compete for breeding territories and pairing occurs upon female choice (GREENWOOD 1980). This may facilitate a sex bias in natal dispersal strategies as well: if the success of territory acquisition is more promising at the familiar natal area, philopatry may be a strategy especially useful for males, while females may reduce the probability of mating with kin via longer NDD. Female-biased NDD of course reduces the probability of inbreeding for the males as well.

The White-tailed Eagle (Haliaeetus albicilla (Linnaeus, 1758); WTE) is a large raptor species distributed across the Palaearctic and Greenland (BIRDLifE INTERNATIONAL 2015). While adult WTEs in most populations stay nearby 
their breeding territory throughout the year, juveniles are vagrant and can move several hundred kilometres away from their natal area (Helander \& Stjernberg 2003, Whitfield et al. 2009b, Nyg̊̊rd et al. 2010). Despite their juvenile vagrancy, similarly to other large raptor species, WTEs are philopatric (i.e. they start breeding relatively close to their natal area), as supported by both ringing data (Helander 2003, Helander \& Stjernberg 2003, StruweJuHl \& GRÜNKorn 2007, WhitFIEld et al. 2009a) and genetic structure of their wild populations (Hailer et al. 2007, Honnen et al. 2010, Nemesházi et al. 2016). Still, some level of long distance gene flow was recently suggested in the Carpathian Basin population (Nemesházi et al. 2016). NDD values published from different WTE populations differ considerably, with mean values ranging from about 30 to $114 \mathrm{~km}$ (Helander 2003, Struwe-JuHL \& GRÜNKORN 2007, Whitfield et al. 2009a). Whitfield et al. (2009a) reported that females dispersed on average two times further than males in the reintroduced population of Western Scotland.

Investigation of large raptor species is challenging; capture of adults on the field is mostly not possible. Therefore, instead of conventional methods, genetic data recovered from non-invasive samples are increasingly used to investigate several topics of individual-based studies, such as annual turnover rate of breeding individuals, parentage, breeding dispersal, or territorial intrusions (RudNick et al. 2005, 2009, Booms et al. 2011, Vili et al. 2013b, Nemesházi et al. 2018). Straightforward methods for investigation of natal dispersal require knowledge on both the hatching and first breeding place of the sampled individuals. Such investigations in large raptors require long-term investments, as several years pass between the hatching and recruitment of individuals (e.g. the first breeding attempt generally occurs around the 6th calendar year in WTEs: HeLANDER \& STJERNBERg 2003). However, spatial genetic structure of breeders can reflect the extent of philopatry as well, as shown in wild populations of several bird species (Double et al. 2005, Temple et al. 2006, Ponnikas et al. 2013). As observations suggest that WTEs are long-term faithful to their territories (Helander 2003, Helander \& Stjernberg 2003, Krone et al. 2013), we assume that breeding dispersal is negligible in this species. Therefore, the scale of their natal dispersal can be inferred indirectly from the genetic relatedness of breeding individuals, even if their hatching places are unknown. This estimated level of natal dispersal can be biased by rare events of breeding dispersal, but such events would influence the estimations of the difference between sexes only if breeding dispersal itself was sex-biased.

We concentrated on two questions in the present study: 1) Is there a fine scale genetic structure within the White-tailed Eagle population of the Carpathian Basin as suggested by the philopatric behaviour of the species? 2) Is there a difference between sexes in pairwise breeding distance of close 
relatives? We assumed that if there is a sex bias in pairwise breeding distance of close relatives, the same stands for a sex bias in natal dispersal distance as well. Both questions were investigated using genotypes of non-invasively sampled breeding individuals across the Carpathian Basin.

\section{MATERIAL AND METHODS}

We used DNA samples collected between 2010 and 2016 by fellow workers of assigned national parks in the Carpathian Basin WTE population (Fig. 1). Moulted feathers were collected during the breeding season within approximately $100 \mathrm{~m}$ distance from nests where breeding attempts were observed. In most regions, moulted feathers were collected and stored as suggested by ViLi et al. (2013a). Resident individuals of each territory were identified based on matching nestling genotypes or the largest number of matching moulted feathers (but at least three) shed by same-sex individuals at the same nest site. Feathers shed by intruders may also occur at occupied nest sites and misidentification of the intruders as breeders could significantly bias the results of investigations concentrat-

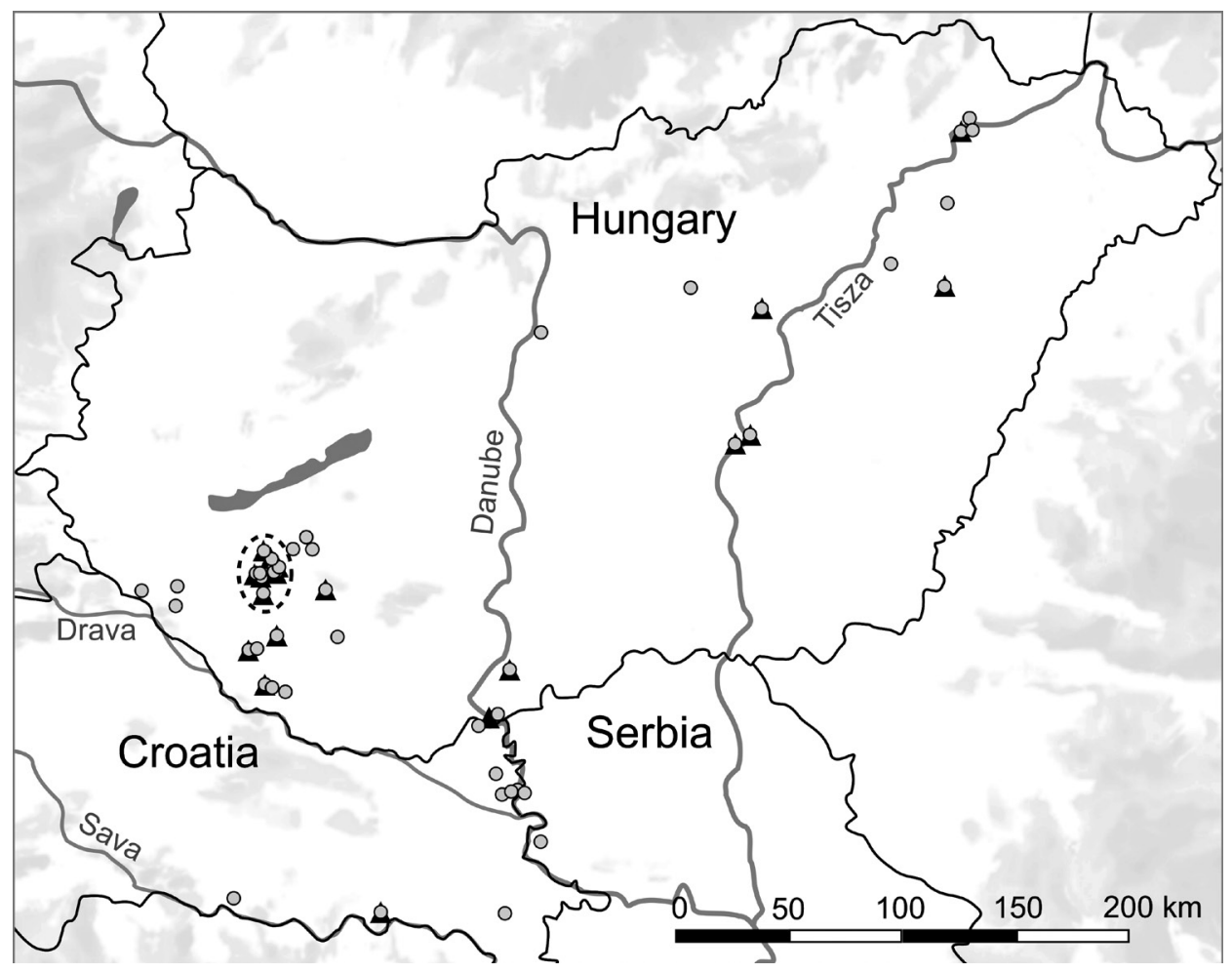

Fig. 1. Nesting locations of breeding White-tailed Eagles sampled across the Carpathian Basin. Black triangles indicate males and grey circles indicate females. In the area depicted by the dashed line overall 12 males and 12 females were sampled 
ing on the breeding population. Nevertheless, our conservative criteria described above were assumed to be adequate for identification of resident WTEs based on non-invasive sampling (Nemesházi et al. 2018). Individuals which did not meet the above criteria were excluded from the further analyses.

DNA was extracted from the superior umbilicus in large feathers (Horváth et al. 2005), and the whole quill below the vane in small ones. DNA purification kits (Quiagen - DNEasy Blood and Tissue Kit or Thermo - GeneJet genomic purification kit) were used following the manufacturers' instructions, with $10 \mu \mathrm{l}$ of $1 \mathrm{M}$ dithiotreitol added during the digestion step.

Sex was identified from feather samples using the 2550F/2718R (Fridolfsson \& ELLEGREN 1999) or the GEfUp/GErUp and GEfLow/GErLow primer pairs (OGDEN et al. 2015). PCR profiles followed the original papers, but PCR profile of the latter was completed by an initial touch-down section where the annealing temperature decreased from 65 to $60^{\circ} \mathrm{C}$ during 7 cycles. PCR products were visualized under UV light ( $2 \%$ agarose gel stained with ECO Safe; Pacific Image Electronics Co., Ltd.).

Each DNA sample was genotyped using 12 microsatellite loci: Hal01, Hal03, Hal04, Hal09, Hal13 (Hailer et al. 2005), Aa27, Aa35, Aa49 (MArtínez-Cruz et al. 2002), IEAAAG04, IEAAAG05, IEAAAG12 and IEAAAG14 (Busch et al. 2005). PCR profiles followed the original papers for Aa and Hal loci, and HAILER et al. (2006) for IEAAAG loci, with some modifications (Nemesházi et al. 2016). Forward primers were 5' labelled with fluorescent dyes $\left(\mathrm{VIC}^{\mathrm{TM}}, \mathrm{FAM}^{\mathrm{TM}}, \mathrm{PET}^{\mathrm{TM}}, \mathrm{NED}^{\mathrm{TM}}\right.$, or HEX) and fragment length analyses were performed on an ABI3130 Genetic Analyzer (Applied Biosystems, using Gene Scan ${ }^{\mathrm{TM}}-500$ LIZ $^{\mathrm{TM}}$ Size Standard). Trace files were scored in Peak Scanner 1.0 (Applied Biosystems). We used Micro-Checker 2.2.3. (VAN Oosterhout et al. 2004) to test for presence of null alleles and scoring errors due to large allele dropout or stutter bands. Genepop 4.2. (Rousset 2008) was used to estimate pairwise linkage disequilibrium across loci. Consensus individual genotypes were prepared manually, based on genotypes of feathers collected at the same nest site (as described in Nemesházi et al. 2018). Probability of identity for combinations of increasing number of loci was calculated with GenAlEx 6.5 (Peakall \& SMouse 2012).

Fine scale genetic structure within the study population was investigated by testing spatial genetic autocorrelation (SMouse \& PeAKall 1999) based on individual genotypes of resident WTEs. Spatial genetic autocorrelation was investigated by two methods: using pairwise genetic distance calculated for co-dominant loci in GenAlEx 6.5 (PeAKall \& SMouse 2012), and kinship coefficient described by Loiselle et al. (1995) in SPAGeDi 1.5a (Hardy \& Vekemans 2002). In these analyses, pairwise Euclidean distances between nest sites of sampled WTEs were used to test whether individual genotypes show random distribution in space; dyads of individuals were grouped into predefined spatial distance classes. GenAlEx calculated a genetic autocorrelation coefficient $(r)$ for each distance class; the statistical significance was tested based on random permutation of individuals across distance classes (no. permutations $=9999$ ) and bootstrap estimates of $r$ (no. bootstraps $=$ 10000). In SPAGeDi, the association between genetic relationship and spatial distances was assessed by averaging the pairwise genetic relationship for each distance class, and statistical significance for spatial genetic structure was tested by 10000 permutations of locations and gene copies. Both in GenAlEx and SPAGeDi, we performed calculations on three datasets: (i) all breeding individuals, (ii) females and (iii) males. Distance classes were defined aiming for each class to contain a reasonably large number of pairwise data (minimum value was 380 for all breeding individuals, 117 for females and 37 for males). As spatial distribution of male-male dyads was aggregated (forming 4 groups: Fig. $2 a$ ), upper limit 
of each distance class was adjusted according to these aggregations, but the first group was divided in two distance classes. We performed this latter subdivision because two of the three datasets (i, iii) contained significantly more dyads between the limits of the first aggregation than between the others'. Accordingly, 5 subsequent distance classes were analysed for spatial autocorrelation, with upper limits of 20, 80, 180, 280 and 400+ km, respectively. Individuals breeding between 0 and $20 \mathrm{~km}$ from each other were grouped in the $20 \mathrm{~km}$ class, those breeding for more than $20 \mathrm{~km}$ up to $80 \mathrm{~km}$ to the $80 \mathrm{~km}$ class, and so on. The last distance class (referred as 400+) differred among datasets, as the longest distance between two sampled males was $420 \mathrm{~km}$, while it was $463 \mathrm{~km}$ between two females as well as between two sampled breeding individuals overall.

To test for a difference between sexes in pairwise breeding distance of close relatives, we calculated Maximum Likelihood pairwise relatedness in ML-Relate (KALINOwsKi et al. 2006) based on allele frequences across all sampled individuals. We previously found this a reliable estimator inspecting real parent-offspring relationships in the Hungarian WTE population (Nemesházi et al. 2017). The expected value of relatedness for close relatives (i.e. siblings or parent and offspring) is 0.5 . We assumed individuals to be closely related if their estimated pairwise relatedness was above 0.4 , since these estimated values scatter around the expected values of relatedness: using the same 12 loci dataset, across 67 real parent-offspring dyads from Hungary, $85 \%$ got a pairwise relatedness value of at least 0.5 , and $91 \%$ got a value greater than 0.4 . In contrast, from 2516 dyads of presumably not related WTEs, 96\% got values below 0.4 (calculated from the results of Nemesházi et al. 2017). Note, that the value 0.4 is closer to 0.5 , than to the expected value of the next level of relatedness ( 0.25 for half-siblings, grandparent and grandchild, etc.). One-tailed Wilcoxon rank sum test was calculated in R 3.1.2. (R CoRe TеАм 2015) to assess whether the distribution of geographic breeding distances of close relative females was shifted towards greater values than that of close relative males; using the function 'wilcox.exact' in the $\mathrm{R}$ package 'exactRankTests'. We used one-tailed test, because where NDD differs among sexes in birds, usually females disperse further (GreEnwood \& HARvey 1982), and female bias was previously found in another WTE population as well (WHITFIELD et al. 2009a). To test for difference in variances across the two sampled groups, we performed Levene's test for homogeneity of variances in geographic distances across closely related males and closely related females; using the function 'leveneTest' in the $\mathrm{R}$ package 'car'.

\section{RESULTS}

We used DNA samples extracted from a total of 214 moulted feathers belonging to 73 resident WTEs across the Carpathian Basin (24 males and 49 females; Fig. 1). Each individual consensus genotype consisted of the full set of 12 loci.

A total of 59 alleles were found; the mean number of alleles across the 12 loci was 4.9, ranging from 2 on Hal03 to 10 on IEAAAG05. Analyses in MicroChecker suggest that our dataset is not influenced by null alleles, large allele dropout or stutter bands. No evidence for pairwise linkage disequilibrium was found across the loci after Bonferroni correction. Probability of identity was estimated at $3.3 \times 10^{-8}$ for 12 loci genotypes, and that for siblings was esti- 
mated at $5.2 \times 10^{-4}$ suggesting that our dataset is reliable for individual-based genetic analyses (i.e. being below or about the magnitude of the threshold of 0.0001, following Waits et al. (2001).

In SPAGeDi, spatial autocorrelation analysis of all breeding individuals $(\mathrm{N}=73)$ showed a moderate, but significant negative relationship between the average pairwise genetic similarity within each distance class and its logaritmic spatial distance (slope $\ln ($ dist $)=-0.0027, p=0.044$ ). However, no such relationship was found based on linear spatial distances, and the observed mean kinship values of each distance class did not significantly differ from that expected under random spatial distribution. GenAlEx also failed to find a relationship between the genetic autocorrelation coefficient $r$ and spatial distance, and no significant deviation of $r$ from zero was observed in any of the distance classes (Fig. 3a). When analysing females ( $N=49$, Fig. $3 b)$ and males

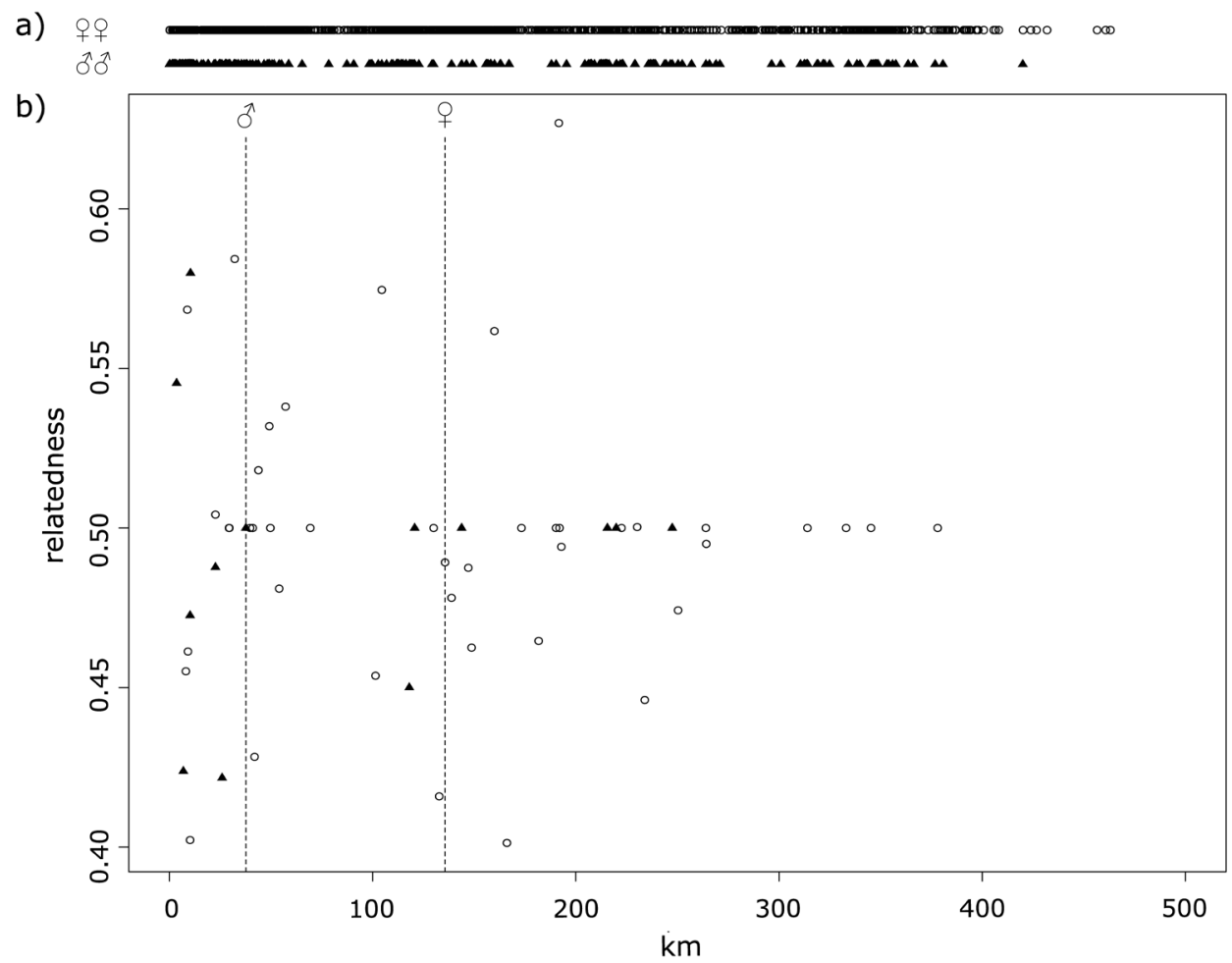

Fig. 2. Pairwise breeding distance of White-tailed Eagles: a = spatial distributions of all investigated same-sex dyads (spatial scale is shown in $b) ; b=$ pairwise spatial distances $(\mathrm{km})$ of individuals with a pairwise Maximum Likelihood relatedness (relatedness) of minimum 0.4. Male-male (triangles) and female-female (circles) dyads are shown separately. Vertical dashed lines indicate the median pairwise breeding distance of related males and that of related females 
( $N=24$, Fig. 3c) separately, both methods failed to find any spatial genetic structure and even the slope for logaritmic spatial distances was nonsignificant for each sex.

Overall 43 female-female and 13 male-male dyads were assumed to consist of closely related individuals, based on their pairwise Maximum Likelihood relatedness being at least 0.4 (Fig. $2 b$; note that these dyads were formed by overall 38 female and 18 male individuals). The maximum breeding distance was $378 \mathrm{~km}$ among related females and $247 \mathrm{~km}$ among related males; median values of breeding distance were 136 and $38 \mathrm{~km}$, respectively. The

a)

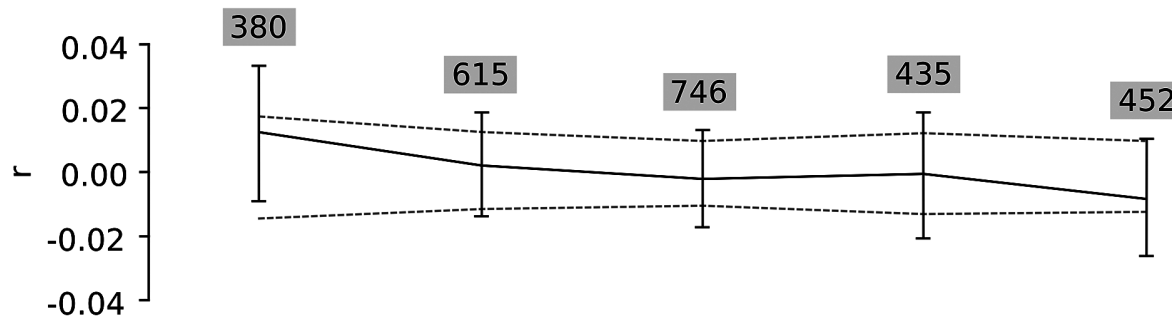

b)

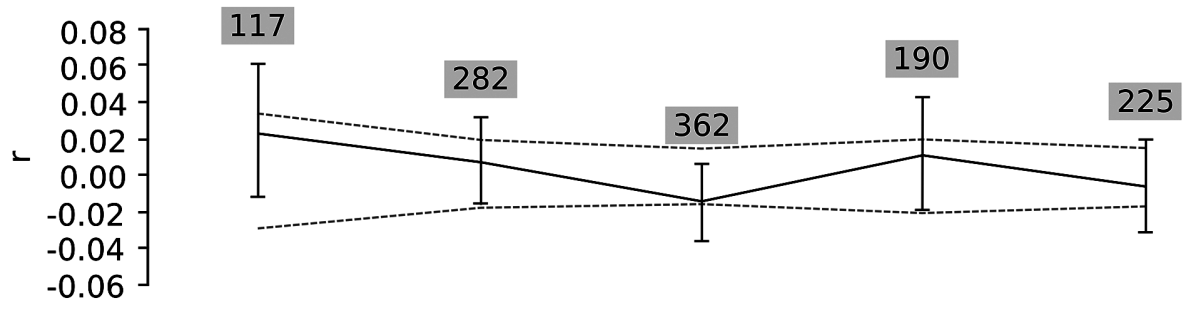

c)

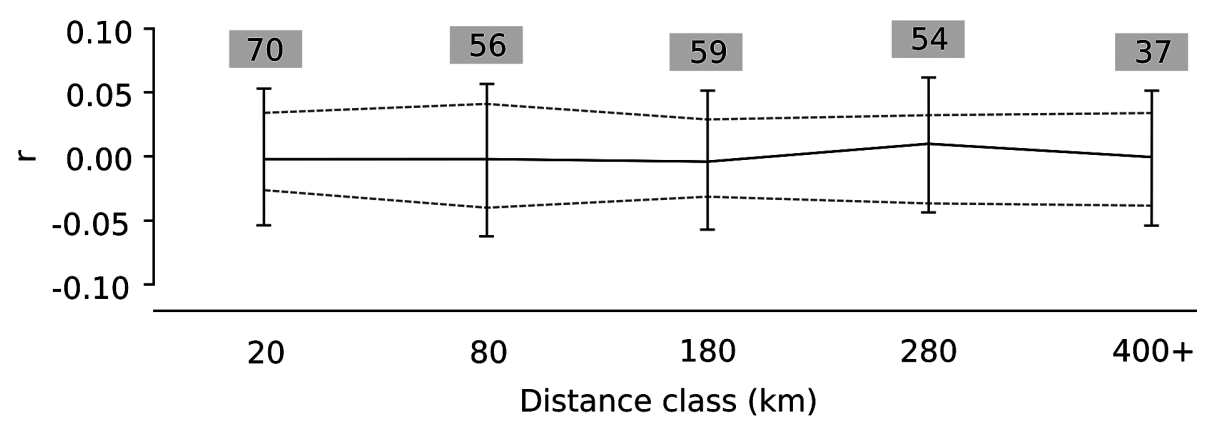

Fig. 3. Correlogram plots of the degree of genetic correlation coefficient $(r$; calculated in GenAlEx) as a function of breeding distance: $\mathrm{a}=$ plot for dyads of all sampled breeders; $\mathrm{b}=$ plot for dyads of females; $\mathrm{c}=$ plot for dyads of males. Dashed lines indicate the permuted 95\% confidence intervals. Bootstrapped 95\% confidence error bars are also shown. Numbers with grey background indicate the numbers of pairwise comparisons (i.e. dyads) within each distance class. Note that the vertical axis scales differ among plots 
Wilcoxon rank sum test revealed that distribution of pairwise geographic distances was significantly shifted towards greater values for close relative females than for close relative males ( $p=0.038, C I$ : 2.609-Inf, $W=371$ ). Levene's test found no significant difference in the variance of geographic distances across related males and related females $(p>0.6)$.

\section{DISCUSSION}

Juvenile White-tailed Eagles (WTE) are vagrant and can travel several hundred kilometres from their natal area (Helander \& Stjernierg 2003, Whitfield et al. 2009b, NyGÅRD et al. 2010), but they tend to start breeding relatively close to it, and the species is therefore assumed to be philopartic (Helander 2003, Helander \& Stjernberg 2003, Whitfield et al. 2009a). Mean natal dispersal distance (NDD) values reported in European WTE populations differ considerably, being below $60 \mathrm{~km}$ in the reintroduced population of Western Scotland (Whitfield et al. 2009a) and exceeding $100 \mathrm{~km}$ in Sweden (Helander 2003). Observations in some WTE populations suggest that NDD can be female biased (Helander 2003, Whitfield et al. 2009a). Lacking sufficient information published from conventional methods in the Carpathian Basin WTE population, we aimed to infer the spatial scale of natal philopatry based on microsatellite genotypes of breeding individuals.

First, we investigated fine scale genetic structure within the study population by testing spatial genetic autocorrelation. This method is known to be effective in highlighting genetic spatial patterns expected in a philopatric population, or under sex-biased dispersal, in the philopatric sex (Double et al. 2005, Temple et al. 2006, Banks \& Peakall 2012, Ponnikas et al. 2013). Namely, relatively high genetic similarity is expected among neighbouring individuals, or across the first few distance classes. Although analyses in SPAGeDi revealed that the slope of the relationship of genetic similarity and logarithmic spatial distance (slope $\ln ($ dist $)$ ) was significantly negative for dyads of WTEs breeding in the Carpathian Basin, both SPAGeDi and GenAlEx failed to find significant deviation from a random spatial distribution of pairwise genetic relatedness values. When we analysed females and males separately, similar lack of fine-scale genetic structure was found, with even the slope $\ln$ (dist) being nonsignificant. Nevertheless, the species is philopatric, as showed both by mark-resight data (Helander 2003, Helander \& Stjernberg 2003, StruWE-JuHl \& GrüNKorn 2007, Whitfield et al. 2009a) and the presence of genetic structure at wide geographical range inferred from microsatellite data (Hailer et al. 2007, Honnen et al. 2010, Nemesházi et al. 2016). Moreover, the Carpathian Basin population maintains a local, unique mitochondrial haplotype as well (Honnen et al. 2010, Nemesházi et al. 2016). Similar contradictions 
of fine-scale spatial genetic and mark-resight data were reported in a lesser kestrel (Falco naumanni) population (AlcAide et al. 2009), where the authors concluded, that rare occurrence of long-distance dispersal events overrode the genetic structure expected in the otherwise philopatric population. Longdistance natal dispersal events have been observed in WTEs as well (STRUWEJuHL \& GRÜNKORN 2007), suggesting that our case with WTEs may be similar to that described by AlCaide et al. (2009) for the lesser kestrels.

In the Finnish WTE population, PonNikAs et al. (2013) reported strong genetic spatial autocorrelation for nestlings, and the mean distance of the highest distance class with significantly positive kinship coefficient corresponded to both ringing data from the Finland population and the known mean natal dispersal distances in the neighbouring population of Sweden. Using the same method for calculating genetic spatial autocorrelation, we failed to find such pattern among breeding WTEs in the Carpathian Basin. Investigating several WTE populations across Europe, Nemesházi et al. (2016) suggested that the impact of immigrants from distant populations may be higher in the Carpathian Basin than in populations to the North. Considering above data we hypothesize that the lack of fine-scale genetic structure in our study despite the known philopatric behaviour of the species is an outcome of some level of long-distance natal dispersal: if such events occur within the population, they increase the average genetic relatedness in higher distance classes, and immigrants may cause a background noise across all distance classes. Our limited sample size, especially in males where genetic similarity within a reduced spatial distance should be higher, may have further increased difficulties for finding fine-scale genetic structure (Banks \& Peakall 2012). Furthermore, the investigated spatial scale may be smaller than the general extent of natal dispersal: in this case, extension of sampling to wider geographical range would be needed to find genetic structure by spatial autocorrelation analyses. However, the fact that the Carpathian Basin maintains a unique genetic composition suggests that natal dispersal in this WTE population is generally restricted to the spatial scale of this region (Nemeshézi et al. 2016). Therefore, the extent of our sampling area should be sufficient for investigation of questions related to natal dispersal in the Carpathian Basin population. Similarly, ringing data of a limited number of individuals seem to confute this possibility: all seven individuals originating from Hungary with known natal dispersal distance remained within the country (unpublished data of the Hungarian Bird Ringing Centre).

As a second objective, we tested whether close relative females disperse at larger distances than close relative males, as suggested by the typical pattern of female-biased natal dispersal in birds. Similar method was used by HaAs et al. (2010) in a Brown-headed Nuthatch (Sitta pusilla Latham, 1790) 
population. Note, that we could only investigate the pairwise breeding distance of individuals, which is not equivalent to the NDD, although related to that. For example, if two close relatives with a pairwise breeding distance of $200 \mathrm{~km}$ were parent and offspring, than the offspring probably indeed had an NDD value of $200 \mathrm{~km}$; as it most probably breeds in its first territory (given that WTEs are long-term faithful to their breeding territories: Helander 2003, Helander \& Stjernberg 2003, Krone et al. 2013). If they were siblings, then the fact that they bred $200 \mathrm{~km}$ apart means that one of them could have dispersed $200 \mathrm{~km}$ while the other one remained completely faithful to the natal area, or both could have dispersed $100 \mathrm{~km}$, or even more, from an area located further from the bee line between the breeding sites of the two individuals. Therefore, although our findings on close relatives with considerable breeding distance up to $378 \mathrm{~km}$ do not explicitly correspond to the NDD, they indicate the occurrence of long-distance natal dispersal. The longest pairwise breeding distances of close relatives found in our study are comparable with the dimensions of the Carpathian Basin. This is in accordance with previous findings based on nestling microsatellite genotypes that the Carpathian Basin maintains one genetic WTE population (Nemesházi et al. 2016). We presumed that the directions of natal dispersal are not sex-biased (Whitfield et al. 2009a), and therefore the relationship of NDD and breeding distance of close relatives should be similar for both sexes.

We found that the median distance of close relative breeding females is bigger than that of close relative males and this result suggests that long-distance natal dispersal events are female-biased in the Carpathian Basin WTE population. Similarly female-biased natal dispersal was found in the reintroduced population of Western Scotland based on mark-resight data, with females dispersing on average two times further than males (WHITFIELD et al. 2009a). Helander (2003) also reported somewhat higher mean NDD for females than for males in Sweden. Female-biased dispersal is common in bird species, and may serve inbreeding avoidance, or may be a consequence of different sex roles derived from their resource defence system (GREENwood \& Harvey 1982, Perrin \& Mazalov 2000). Our findings suggest that sexbiased natal dispersal contribute to the generally low pairwise intersexual relatedness of WTEs breeding close to each other in Southwestern Hungary (Nemesházi et al. 2018).

Despite the known philopatry of the species, our spatial autocorrelation analyses generally failed to show evidence of spatial genetic structure within the Carpathian Basin or gave only a weak evidence of it. We assume that this contradiction is due to occurrence of long-distance natal dispersal events together with our limited sample size (and maybe the limited spatial scale). On the other hand, the comparison of pairwise breeding distances of closely 
related same-sex individuals revealed a significant female bias. We conclude that long-distance natal dispersal events in the Carpathian Basin are femalebiased, in accordance with a limited number of previous reports on sex-biased NDD in other European WTE populations. This bias may be a consequence of the territorial behaviour of the males: if a recruiting young male has better chances to acquire a good territory near its natal place then male philopatry imposes a pressure on females to avoid mating with kin by dispersal. Furthermore dispersal can be advantageous if resources show spatio-temporal variation or because it reduces competition with kin. For WTEs these latter advantages of dispersal seem not to differ between the sexes thus we think these are less likely to account for the female-biased pattern we found.

Acknowledgements - Moulted feathers in Eastern Hungary were provided by Gábor Tihanyi. Some of the feathers from Southwestern Hungary were collected by Attila Mórocz, Tamás Nyemcsok, Andrea Schulcz, Balázs Szelényi and Attila Bereczky. Genetic data of Croatian and Serbian individuals were available from our former study, in collaboration with Tibor Mikuska and István Hám. Nóra Vili helped with useful suggestions for the final touches of the manuscript. We also thank for the insightful suggestions of an anonymous reviewer. Laboratory work was funded by the Normative Research Funding Committee of the Szent István University.

\section{REFERENCES}

Alcaide, M., Serrano, D., Tella, J. L. \& Negro, J. J. (2009): Strong philopatry derived from capture-recapture records does not lead to fine-scale genetic differentiation in lesser kestrels. - The Journal of Animal Ecology 78(2): 468-475. https://doi.org/10.1111/j.13652656.2008.01493.x

BANKs, S. C. \& PEAKall, R. (2012): Genetic spatial autocorrelation can readily detect sexbiased dispersal. - Molecular Ecology 21(9): 2092-2105. https://doi.org/10.1111/j.1365294X.2012.05485.x

BirdLife International (2015): Haliaeetus albicilla. The IUCN Red List of Threatened Species 2015: e.T22695137A80155303. https://doi.org/10.2305/IUCN.UK.2015-4.RLTS. T22695137A80155303.en. [Downloaded on 11 September 2016]

Booms, T. L., Talbot, S. L., Sage, G. K., McCaffery, B. J., McCracken, K. G. \& Schempf, P. F. (2011): Nest-site fidelity and dispersal of gyrfalcons estimated by noninvasive genetic sampling. - The Condor 113(4): 768-778. https://doi.org/10.1525/cond.2011.100178

Busch, J. D., Katzner, T. E., Bragin, E. \& Keim, P. (2005): Tetranucleotide microsatellites for aquila and haliaeetus eagles. - Molecular Ecology Notes 5(1): 39-41. https://doi. org/10.1111/j.1471-8286.2004.00823.x

Double, M. C., Peakall, R., Beck, N. R. \& Cockburn, A. (2005): Dispersal, philopatry, and infidelity: dissecting local genetic structure in superb fairy-wrens (Malurus cyaneus). - Evolution 59(3): 625-635. 
Fridolfsson, A.-K. \& Ellegren, H. (1999): A simple and universal method for molecular sexing of non-ratite birds. - Journal of Avian Biology 30(1): 116-121.

Greenwood, P. J. (1980): Mating systems, philopatry and dispersal in birds and mammals. - Animal Behaviour 28(4): 1140-1162. https://doi.org/10.1016/S0003-3472(80)80103-5

Greenwood, P. J. \& Harvey, P. H. (1982): The natal and breeding dispersal of birds. - Annual Review of Ecology and Systematics 13(1): 1-21. https://doi.org/10.1146/annurev. es.13.110182.000245

HaAs, S. E., Cox, J. A., Smith, J. V. \& Kimball, R. T. (2010): Fine-scale spatial genetic structure in the cooperatively breeding brown-headed nuthatch (Sitta pusilla). - Southeastern Naturalist 9(4): 743-756. https://doi.org/10.1656/058.009.0409

Hailer, F., Gautschi, B. \& Helander, B. (2005): Development and multiplex PCR amplification of novel microsatellite markers in the White-tailed Sea Eagle, Haliaeetus albicilla (Aves: Falconiformes, Accipitridae). - Molecular Ecology Notes 5(4): 938-940. https://doi.org/10.1111/j.1471-8286.2005.01122.x

Hailer, F., Helander, B., Folkestad, A. O., Ganusevich, S. A., Garstad, S., Hauff, P., Koren, C., Masterov, V. B., Nygård, T., Rudnick, J. A., Shiraki, S., Skarphedinsson, K., Volke, V., Wille, F. \& Vilì, C. (2007): Phylogeography of the white-tailed eagle, a generalist with large dispersal capacity. - Journal of Biogeography 34(7): 1193-1206. https://doi.org/10.1111/j.1365-2699.2007.01697.x

Hailer, F., Helander, B., Folkestad, A. O., Ganusevich, S. A., Garstad, S., Hauff, P., Koren, C., NygÅrd, T., Volke, V., Vilà, C. \& Ellegren, H. (2006): Bottlenecked but longlived: high genetic diversity retained in white-tailed eagles upon recovery from population decline. - Biology Letters 2(2): 316-319. https://doi.org/10.1098/rsbl.2006.0453

Hardy, O. J. \& Vekemans, X. (2002): SPAGeDi: a versatile computer program to analyse spatial genetic structure at the individual or population levels. - Molecular Ecology Notes 2(4): 618-620. https://doi.org/10.1046/j.1471-8286.2002.00305.x

Helander, B. (2003): The international colour-ringing programme - Adult survival, homing, and the expansion of the white-tailed sea eagle in Sweden. Pp. 145-154. In: HeLander, B., Marquis, M., Bowerman, B. (eds): Sea Eagle 2000. - Swedish Society for Nature Conservation (SNF), Björkö, Sweden, 13-17 September 2000.

Helander, B. \& Stjernberg, T. (2003): Action plan for the conservation of white-tailed sea eagle (Haliaeetus albicilla). - BirdLife International Sweden, Strasbourg, 42 pp.

Honnen, A.-C., Hailer, F., Kenntner, N., Literák, I., Dubská, L. \& Zachos, F. E. (2010): Mitochondrial DNA and nuclear microsatellites reveal high diversity and genetic structure in an avian top predator, the white-tailed sea eagle, in central Europe. Biological Journal of the Linnean Society 99(4): 727-737. https://doi.org/10.1111/j.10958312.2010.01373.x

Horváth, M. B., Martínez-Cruz, B., Negro, J. J., Kalmár, L. \& Godoy, J. A. (2005): An overlooked DNA source for non-invasive genetic analysis in birds. - Journal of Avian Biology 36(1): 84-88. https://doi.org/10.1111/j.0908-8857.2005.03370.x

Kalinowski, S. T., Wagner, A. P. \& TAPer, M. L. (2006): ML-Relate: A computer program for maximum likelihood estimation of relatedness and relationship. - Molecular Ecology Notes 6(2): 576-579. https://doi.org/10.1111/j.1471-8286.2006.01256.x

Krone, O., Nadjafzadeh, M. \& Berger, A. (2013): White-tailed sea eagles (Haliaeetus albicilla) defend small home ranges in north-east Germany throughout the year. - Journal of Ornithology 154(3): 827-835. https://doi.org/10.1007/s10336-013-0951-6 
Loiselle, B. A., Sork, V. L., Nason, J. \& Graham, C. (1995): Spatial genetic structure of a tropical understory shrug, Psychotria officinalis (Rubiaceae). - American Journal of Botany 82(11): 1420-1425. https://doi.org/10.2307/2445869

Martínez-Cruz, B., David, V. A., Godoy, J. A., Negro, J. J., O’Brien, S. J. \& Johnson, W. E. (2002): Eighteen polymorphic microsatellite markers for the highly endangered Spanish imperial eagle (Aquila adalberti) and related species. - Molecular Ecology Notes 2(3): 323-326. https://doi.org/10.1046/j.1471-8278.2002.00231.x

Matthysen, E. (2005): Density-dependent dispersal in birds and mammals. - Ecography 28(3): 403-416. https://doi.org/10.1111/j.0906-7590.2005.04073.x

Monti, F., Delfour, F., Arnal, V., Zenboudji, S., Duriez, O. \& Montgelard, C. (2018): Genetic connectivity among osprey populations and consequences for conservation: philopatry versus dispersal as key factors. - Conservation Genetics: first online 1-13. https://doi.org/10.1007/s10592-018-1058-7

Nemesházi, E., Kövér, S., Zachos, F. E., Horváth, Z., Tihanyi, G., Mórocz, A., Mikuska, T., Hám, I., Literák, I., Ponnikas, S., Mizera, T. \& Szabó, K. (2016): Natural and anthropogenic influences on the population structure of white-tailed eagles in the Carpathian Basin and Central Europe. - Journal of Avian Biology 47(6): 795-805. https:// doi.org/10.1111/jav.00938

Nemesházi, E., Szabó, K., Horváth, Z. \& Kövér, S. (2018): The effects of genetic relatedness on mate choice and territorial intrusions in a monogamous raptor. - Journal of Ornithology 159(1): 233-244. https://doi.org/10.1007/s10336-017-1494-z

Nygård, T., Bevanger, K., Dahl, E. L., Flagstad, Ø., Follestad, A., Hoel, P. L., May, R. \& Reitan, O. (2010): A study of white-tailed eagle Haliaeetus albicilla movements and mortality at a wind farm in Norway. Pp. 1-4. In: Climate Change and Birds. - British Ornithologists' Union, Peterborough. https://www.bou.org.uk/bouprocnet/climatechange-and-birds/

Ogden, R., Heap, E., McEwing, R., Tingay, R. \& Whitfield, D. P. (2015): Population structure and dispersal patterns in Scottish Golden Eagles Aquila chrysaetos revealed by molecular genetic analysis of territorial birds. - Ibis 157(4): 837-848. https://doi. org/10.1111/ibi.12282

Ortego, J., Aparicio, J. M., Cordero, P. J. \& Calabuig, G. (2008): Individual genetic diversity correlates with the size and spatial isolation of natal colonies in a bird metapopulation. - Proceedings of the Royal Society B: Biological Sciences 275(1646): 2039-2047. https://doi.org/10.1098/rspb.2008.0475

Peakall, R. \& Smouse, P. E. (2012): GenAlEx 6.5: genetic analysis in Excel. Population genetic software for teaching and research - an update. - Bioinformatics 28(19): 25372359. https://doi.org/10.1093/bioinformatics/bts460

Perrin, N. \& Mazalov, V. (2000): Local competition, inbreeding, and the evolution of sex-biased dispersal. - The American Naturalist 155(1): 116-127. https://doi.org/10.1086/303296

Ponnikas, S., Kvist, L., Ollila, T., Stjernberg, T. \& Orell, M. (2013): Genetic structure of an endangered raptor at individual and population levels. - Conservation Genetics 14(6): 1135-1147. https://doi.org/10.1007/s10592-013-0501-z

Pusey, A. E. (1987): Sex-biased dispersal and inbreeding avoidance in birds and mammals. Trends in Ecology \& Evolution 2(10): 295-9. https://doi.org/10.1016/0169-5347(87)90081-4

R Core TeAm (2015): R: A language and environment for statistical computing. - R Foundation for Statistical Computing, Vienna, Austria. R ver. 3.1.2. http://www.r-project.org

Rousset, F. (2008): Genepop'007: a complete re-implementation of the Genepop software for Windows and Linux. - Molecular Ecology Resources 8(1): 103-106. https://doi. org/10.1111/j.1471-8286.2007.01931.x 
Rudnick, J. A., Katzner, T. E., Bragin, E. A., Rhodes, O. E. \& DeWoody, J. A. (2005): Using naturally shed feathers for individual identification, genetic parentage analyses, and population monitoring in an endangered Eastern imperial eagle (Aquila heliaca) population from Kazakhstan. - Molecular Ecology 14(10): 2959-2967. https://doi. org/10.1111/j.1365-294X.2005.02641.x

Rudnick, J. A., KATZNER, T. E. \& DeWoody, J. A. (2009): Genetic analyses of noninvasively collected feathers can provide new insights into avian demography and behavior. Pp. 181-197. In: Aronoff, J. B. (ed.): Handbook of nature conservation. - Nova Science Publishers Inc., New York.

Sмiтh, S. M. (1978): The "underworld" in a territorial sparrow: adaptive strategy for floaters. - The American Naturalist 112(985): 571-582.

Smouse, P. E. \& PeAKall, R. (1999): Spatial autocorrelation analysis of individual multiallele and multilocus genetic structure. - Heredity 82: 561-573. https://doi.org/10.1038/ sj.hdy.6885180

StruWE-JuHL, B. \& GRÜNKoRn, T. (2007): Ergebnisse der Farbberingung von Seeadlern Haliaeetus albicilla in Schleswig-Holstein mit Angaben zu Ortstreue, Umsiedlung, Dispersion, Geschlechtssreife, Altersstruktur und Geschwisterverpaarung. - Vogelwelt 128: 117-129.

Temple, H. J., Hoffman, J. I. \& Amos, W. (2006): Dispersal, philopatry and intergroup relatedness: Fine-scale genetic structure in the white-breasted thrasher, Ramphocinclus brachyurus. - Molecular Ecology 15(11): 3449-3458. https://doi.org/10.1111/j.1365294X.2006.03006.X

Van Oosterhout, C., Hutchinson, W. F., Wills, D. P. M. \& Shipley, P. (2004): Micro-Checker: software for identifying and correcting genotyping errors in microsatellite data. Molecular Ecology Notes 4(3): 535-538. https://doi.org/10.1111/j.1471-8286.2004.00684.x

Vili, N., Nemesházi, E., Kovács, S., Horváth, M., Kalmár, L., \& Szabó, K. (2013a): Factors affecting DNA quality in feathers used for non-invasive sampling. - Journal of Ornithology 154(2): 587-595. https://doi.org/10.1007/s10336-013-0932-9

Vili, N., Szabó, K., Kovács, S., Kabai, P., Kalmár, L. \& Horváth, M. (2013b): High turnover rate revealed by non-invasive genetic analyses in an expanding Eastern Imperial Eagle population. - Acta Zoologica Academiae Scientiarum Hungaricae 59(3): 279-295.

Waits, L. P., Luikart, G. \& Taberlet, P. (2001): Estimating the probability of identity among genotypes in natural populations: cautions and guidelines. - Molecular Ecology 10(1): 249-256. https://doi.org/10.1046/j.1365-294X.2001.01185.x

Whitfield, D. P., Douse, A., Evans, R. J., Grant, J., Love, J., McLeod, D. R. A., Reid, R., \& WiLson, J. D. (2009a): Natal and breeding dispersal in a reintroduced population of White-tailed Eagles Haliaeetus albicilla. - Bird Study 56(2): 177-186. https://doi. org/10.1080/00063650902792023

WhitField, D. P., DuffY, K., MCLeOd, D. R. A., Evans, R. J., MacLennan, A. M., Reid, R., Sexton, D., Wilson, J. D. \& Douse, A. (2009b): Juvenile dispersal of white-tailed eagles in Western Scotland. - Journal of Raptor Research 43(2): 110-120. https://doi. org/10.3356/JRR-08-54.1

Yoder, J. M., MARSChAll, E. A. \& Swanson, D. A. (2004): The cost of dispersal: predation as a function of movement and site familiarity in ruffed grouse. - Behavioral Ecology 15(3): 469-476. https://doi.org/10.1093/beheco/arh037

Received September 18, 2017, accepted June 8, 2018, published August 1, 2018 